through the chemistry of the hormones involved in lactation to chapters on the growth and development of the mammary gland, hormonal control of milk secretion and milk ejection, assays for the hormones and a section on hormonal receptors and their mechanisms. In these it is possible to gain a comparative picture, as far as our knowledge will allow, of the hormonal requirements for mammary development in species as diverse as the Californian leafnosed bat, rabbit and monkey. Indeed, the book emphasizes how limited is our knowledge of the endocrine events controlling not only lactation but reproduction as a whole in the vast majority of mammals.

It is satisfying to see that the authors have included the human being in their considerations. Too often in the past has knowledge gained from animals been ignored or remained unknown in clinical practice, as is clearly illustrated in the section on milk ejection. Some 5,000 years ago milkers were aware that an agitated cow did not give milk readily. Similarly, Cooper in 1840 stated that successful breast-feeding also needs a calm and tranquil mind, a point which many busy post-natal wards in the modern hospital would do well to remember.

It is clear that many of the recent advances in the field covered by this book have resulted from detailed studies using radioimmunoassays of the hormones involved. As the authors discuss, it is salutary to remember that these methods do not necessarily measure the biological activity of these hormones: will our ideas again need changing when true bioactivity is measured?

A minor criticism is the inclusion of many illustrations from the authors' own studies when, in some instances, others would have been more informative. Nevertheless I found this book easy to read, full of invaluable information and in parts enjoyable; for example, one of the authors describes the time when, having previously worked with milligram quantities, he received a bottle containing half a kilogram of crystalline progesterone for studies on the induction of lactation.

This monograph is well presented and should become a standard reference for all those interested in lactation.

Alan S. McNeilly is a Research Scientist in the MRC Unit of Reproductive Biology, Edinburgh.

\title{
What's new in hybridoma technology?
}

\section{Carlo M. Croce}

Monoclonal Antibodies. Hybridomas: $A$ New Dimension in Biological Analyses. Edited by R.H. Kennett, T.J. McKearn and K.B. Bechtol. Pp.423. ISBN 0-30640408-7. (Plenum Press: 1980.) \$22.50, $£ 18.59$.

THE possibility of producing hybridomas secreting monoclonal antibodies of predefined specificities has changed the field of immunology considerably and has provided powerful reagents for biomedical investigation. This book is an attempt to summarize the most recent developments in this area of research.

The book is divided into two major sections. The first concerns the production of hybridomas and the many possible applications of hybridoma technology, for example in studies of the structure and the genetics of immunoglobulins, in the study of the cell surface, in the definition of antigens specific for cells of different lineages and for cells at different stages of differentiation, and in the study of human tumour-associated antigens. Considerable emphasis is given to the analysis of the cell surface by the use of monoclonal antibodies. The second and much smaller section is an appendix cataloguing various methods for the production and the characterization of monoclonal antibodies. A short summary of every technique related to the production, storage and characterization of hybridoma clones is also included.

This book will be of considerable help to investigators who are not familiar with tissue culture and somatic cell fusion techniques and who intend to produce hybridomas secreting monoclonal antibodies for a variety of purposes. It also provides a good overview of some of the most recent applications of hybridoma technology, particularly in the study of the cell surfaces of malignant cells and of cells of different lineages or stages of differentiation. Although the articles are, in general, well presented and informative, they are rather repetitious in that similar studies carried out in different laboratories are described. It would have been much more useful, I believe, if the editors had included only those articles that reflect the "state of the art" in the areas of application of the monoclonal antibodies to biomedical research. They might also have added an overview of some of the more important contributions in this area.

Overall, this volume provides the necessary information to carry out experiments involving monoclonal antibodies and should be an asset to investigators who wish to become familiar with hybridoma technology.

Carlo M. Croce is Associate Director of The Wistar Institute, Philadelphia.
Anthozoan beauty

\section{C.M. Yonge}

British Anthozoa. Synopses of the British Fauna, 18. By R.L. Manuel. Pp.241. ISBN 0-12-470050-0. (Academic: 1981.) £7.50, \$18.

THIS is the latest and, next but one, the largest of the Synopses of the British Fauna. The series is admirably edited by Doris Kermack on behalf of the Linnean

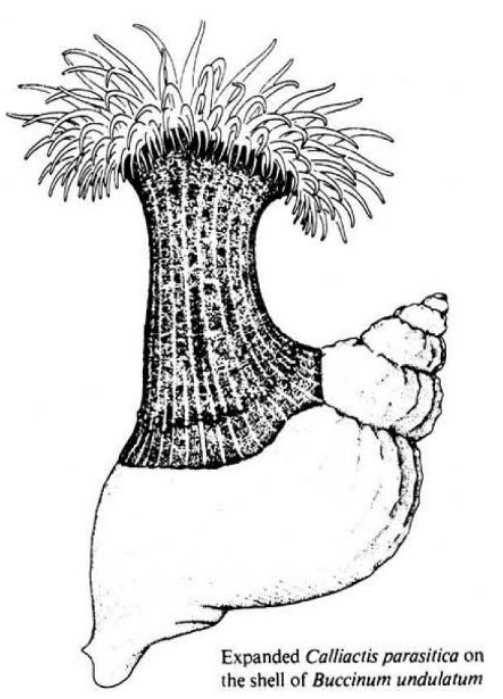

Society in cooperation, in recent parts, with R.S.K. Barnes of the Estuarine and Brackish-water Sciences Association.

While the Anthozoa, in the form of stony, horny and soft corals, flourish most abundantly in shallow tropical waters, the British fauna comprises no less than 73 species. The greatest number are sea anemones, among them six species of the closely related ahermatypic (non-reefbuilding) corals, three cerianthids (one only known in the larval state) and eight zoanthids. The octocorallines are represented by alcyonarians such as the well-known dead-man's fingers (Alcyonium digitatum L.), together with two gorgonids (rockattached sea fans) and four pennatulids (sea pens) that live unattached but erect in bottom muds.

Most anthozoans, particularly the anemones, are animals of great beauty of colour and delicate design. They have to be described when alive and fully expanded. An extremely high standard of illustration was set by Philip Henry Gosse in Actinologia Britannica (1860) and by Alan Stephenson in the two volumes of his Ray Society British Sea Anemones (1928, 1935). This book has a wider coverage and, although inevitably denied colour and with only two pages of photographs, the line drawings, largely of living animals and showing pattern and texture, are so beautifully executed as fully to maintain this standard. This is an altogether admirable guide.

Sir Maurice Yonge is an Honorary Fellow in Zoology at the University of Edinburgh. 